Article

\title{
Containing Volatility: Windfall Revenues for Resource-Rich Low-Income Countries*
}

\author{
Anton Dobronogov ${ }^{\dagger} \quad$ Octave Keutiben ${ }^{\ddagger}$
}

\begin{abstract}
An abundance of natural resources is both an opportunity and a challenge for developing countries. Several resource-rich, low-income countries receive amounts of foreign aid that are similar to or larger than their actual or potential revenues from natural resources. In such countries, the donors may have an opportunity to help a government to use its resource revenues productively and minimize the magnitude of risks created by resource rents. Development of aid instruments tailored for such purposes might be helped by model-based analysis of the effects of foreign aid on resourcerich, low-income economies and its interactions with the flows of natural resource revenues. This paper develops a growth model à la Barro in which the government receives windfalls (from natural resources and foreign aid) and rent-seeking agents contest for public funds. The key conclusion is that making aid countercyclical helps to achieve higher economic growth, and so does conditioning disbursements on enhancement of public capital. Introducing elements of insurance in the design of both aid products financing investments in infrastructure and social services and supporting policy and institutional reforms may help to achieve both of these objectives.
\end{abstract}

Keywords: Economic growth; Foreign aid; Natural resources; Rent-seeking; Volatility JEL classification: D72; F35; O43; Q33

${ }^{*}$ We thank Phil Keefer, Fulbert Tchana Tchana, Nelnan Koumtingue, Kevin Carey, and Sebastien Dessus for helpful comments. All errors are ours.

†World Bank, 1818 H Street, NW, Washington, DC 20433, USA. adobronogov@worldbank.org

$¥$ Department of Economics, Université de Moncton, Campus de Moncton, 18 avenue AntonineMaillet, Moncton, NB, E1A 3E9, Canada. Email: octave.keutiben@umoncton.ca 


\section{Introduction}

Abundance of natural resources is both an opportunity and a challenge for developing countries. One may expect a positive impact if the country's policies and institutions are conducive for accelerating accumulation of physical and human capital. The discovery and development of natural resources can help to increase the economy's investment rate, bringing about faster economic growth in the short run. Further, revenues generated from these resources can be used to enhance social outcomes related to health and education that induce economic growth in the long run. These revenues may also help growth by allowing the governments to finance their expenditures with lower levels of taxation of economic activity.

However, if not handled well, natural resources adversely affect economic growth , particularly in low-income countries. ${ }^{1}$ Natural resource revenues are intrinsically temporary and highly volatile (for example, the price of Brent oil varied between $\$ 9$ and $\$ 157$ during the 1999-2009 period). Cash flows from natural resources cause an appreciation of the real exchange rate, thus shifting factors of production out of technologically sophisticated activities with positive spillovers to other sectors of the economy such as manufacturing, and producing a phenomenon known as Dutch Disease. An increase in oil revenues owing to a rise in oil prices or increased production drives up the real exchange rate, causing domestic production of exportables to drop and imports to rise. Problems occur if the increased revenues prove temporary. Reversing the above scenario through depreciation often proves difficult, and repeated boom-bust cycles will lower investment in domestic production of tradable goods. Because most innovation and technological progress

\footnotetext{
${ }^{1}$ See Frankel (2012) for a more detailed review of these effects.
} 
take place in the tradable sector, shifting resources into the less dynamic nontradable sector can have long-term consequences for economic growth. Resource-rich economies vulnerable to Dutch Disease remain highly dependent on revenues derived from those resources and therefore exhibit boom-bust cycles in their growth performance.

In economies where a large portion of revenues accrues to the public sector, public expenditure initiates the cycle, as government spending increases and decreases with the rise and fall of revenue. An obvious solution would be to smooth government expenditure, with the government saving all or part of the windfall during upswings and drawing down assets to maintain expenditure during the bust. If the government is to accumulate assets during booms, it must establish a stabilization fund. The objective of the policy is not to prevent real appreciation per se, which would be impossible if any benefit were to be derived from the oil, but rather to prevent the volatility associated with the boom-bust cycle. ${ }^{2}$

Unfortunately, the political economy of most resource-rich countries is not conducive to strengthening the policies and institutions needed to avoid procyclical spending, and high price volatility further challenges these policies and institutions. A country rich in natural resources may feel a false sense of security that leads the government to focus on distribution of the resource rents and to delay implementation of necessary economic reforms and other growth-enhancing policies. Among other things, the government may blunt demands for reform by adopting economically inefficient but politically effective patronage policies.

Abundance of natural resource rents may cause wasteful rent-seeking. Exten-

\footnotetext{
${ }^{2}$ In principle, the deleterious consequences of real appreciation can be avoided by basing spending on a stable stream of income rather than on volatile current revenue.
} 
sive state intervention, usually accompanied by meager accountability and transparency at the implementation stage, invites resource-wasting competition for favorable bureaucratic treatment. A windfall gain, such as higher oil revenues, may lead to intensified rent-seeking, a more-than-proportional rise in fiscal redistribution, and lower growth-a phenomenon known as the voracity effect (Lane and Tornell, 1996). Rent-seeking may take many forms, from corruption to civil war. In the resource-rich countries of Latin America, central governments have permitted extensive rent-seeking by subnational governments, state-owned companies, and the military, institutions that have limited incentives to minimize costs and in fact may have incentives to overspend so as to qualify for increased transfers. The result has been political instability and short-sighted policies, both of which make it very difficult to carry out economic reforms (Dornbusch and Edwards, 1991).

As a result, stabilization funds in low-income environments are at risks of becoming institutions for fiscal transfers from fiscally responsible to fiscally irresponsible governments if deterioration of governance over time is not avoided (Collier, 2007). Resources accumulated in the fund represent a rent which can be fought for, unless the quality of the country's institutions is sufficiently high to prevent that from happening, so while a stabilization fund might become a useful tool enhancing macroeconomic stability, in certain circumstances it may also increase incentives for rent-seeking and thus contribute to institutional deterioration.

Large-scale foreign aid is another factor which may affect the impact of resource revenues on economic development in low-income resource-rich countries. A number of low-income countries receive amounts of foreign aid (typically, from a large number of donors and in a variety of forms) which are similar to or larger than their actual or potential revenues from natural resources. For example, three 
countries from the Great Lakes region, Burundi, Democratic Republic of Congo, and Uganda, all of which have substantial discovered reserves of oil and minerals, are also reported by OECD's Development Assistance Committee to receive official development assistance of the magnitude equivalent to double-digit percentages of their respective GDPs. In a resource-rich low-income country, the donors may have an opportunity to help a government to use its resource revenues productively and minimize the magnitude of risks created by resource rents. As their natural resource revenues increase, these countries will be facing an opportunity of transition from aid dependency to greater fiscal self-sufficiency. During this transition period, macroeconomic and institutional impact of the oil revenues on the economies of low-income countries will much depend on the amounts and the structure of foreign aid being delivered after the oil revenues start flowing in. There are two principal channels through which foreign aid may interact with resource revenues.

First, foreign aid may potentially help to stabilize the government revenues, making it easier for a country with limited institutional quality to stabilize expenditures. This will happen if amounts of aid are systematically countercyclical with respect to oil revenues (or with respect to oil prices if production remains relatively stable). In principle, this can be achieved, but is by no means automatic. On average, foreign aid is in fact mildly pro-cyclical. ${ }^{3}$ Since the donor agencies have incentives to disburse aid according to pre-determined targets, during the periods when oil revenues are rapidly increasing they may supply amount of resources which may exceed what the government can spend with reasonable efficiency and

\footnotetext{
${ }^{3}$ See Perry (2009) for a review of the relevant literature.
} 
effectiveness.

Second, a trajectory for substitution of oil revenues for aid will determine whether the countries will receive support with resolving the problems they are not yet institutionally equipped to handle. Collier (2006) has shown that on average aid has been more effective at promoting development than oil revenues, predominantly because of complementary inputs by the donors, such as technical assistance and scrutiny of public expenditures.

Major change in the scale and structure of the government's own revenues calls for a corresponding change in design of the foreign aid programs. Typically, donors gear such efforts towards strengthening institutions for oil wealth management by means of conditionality and technical assistance - that is, towards improving government's capacity to absorb financial resources productively. These undoubtedly useful efforts need to be complemented by changes in design of aid instruments helping to stabilize the government's overall revenues. If such changes are made only ad-hoc in response to deterioration in the quality of the country's institutions and economic performance after it occurs, critical time will be lost. Development of such instruments might be helped by model-based analysis of the effects of foreign aid instruments on resource-rich low-income economies and their interactions with the flows of natural resource revenues. Economic effects of aid and natural resource revenues have been examined separately, though frequently compared, in the literature. ${ }^{4}$ Our paper contributes to this body of work by developing a model which offers a coherent analytical framework for looking at these effects jointly. ${ }^{5}$

\footnotetext{
${ }^{4}$ See Morrison (2012) for a review of this literature.

${ }^{5}$ To the best of our knowledge no model has looked at these effects jointly before.
} 
We develop a growth model à la Barro in which the government simultaneously receives windfalls from natural resources and foreign aid, and rent-seeking agents contest for public funds. By jointly considering foreign aid and natural resource revenues, we show that making aid countercyclical helps to achieve higher economic growth, and so does conditioning disbursements on enhancement of public capital.

The remainder of the paper is organized as follows. Section 2 outlines the analytical framework and its key characteristics. Section 3 characterizes the solution of the model and discuss the main results. Section 4 highlights some policy implications and concludes.

\section{The model}

Our baseline model is an extension of Hodler (2007) accounting explicitly for natural resource revenues. We consider a resource-rich country who produces and consumes a single commodity. There are private agents and government. Government revenue can come from foreign aid, resource rents, and income tax. Private agents can allocate labor to output production or to rent-seeking activities. ${ }^{6}$

\subsection{Private agents}

There is a continuum of private agents of measure 1. Each agent $i$ is endowed with one time unit at each date $t$, a fraction $l_{i t}$ of which can be devoted to labor supply in the productive sector, and the balance, $1-l_{i t}$, to rent seeking. At each

\footnotetext{
${ }^{6} \mathrm{By}$ considering a one sector growth economy, our model mainly focus on resource curse causes by the volatility of natural resource revenues or weak institutions rather than on Dutch Disease.
} 
period $t$, agent $i$ can generate income by producing output $y_{i t}$ and by appropriating rents $b_{i t}$ from government revenue. The production technology is given by

$$
y_{i t}=A k_{i t}^{\alpha}\left(l_{i t} g_{t}\right)^{1-\alpha}
$$

where $\alpha \in(0,1)$ and $A>0 . k_{i t}$ denotes the physical capital input of agent $i$ at date $t$ and $g_{t}$ is the stock of productive public capital (public infrastructure). The economy is initially endowed with a stock of public capital $g_{0}>0$ considered as given. ${ }^{7}$ The produced income can be used for current private consumption $c_{i t}$ and to accumulate private capital $k_{i t}$, whereas the usurped income contributes directly to the utility of agents. ${ }^{8}$ Hence, given the initial endowment in the stock of private capital $k_{i 0}=k_{0}$, the capital accumulation constraint for each individual $i$ is described by

$$
k_{i t+1}=\left(1-\tau_{t}\right) y_{i t}-c_{i t}+\left(1-\delta_{k}\right) k_{i t}
$$

where $\tau_{t} \in[0,1)$ is a proportional tax rate on income and $\delta_{k} \in[0,1]$ is the rate of depreciation of private capital. The appropriation technology is such that agent $i$

\footnotetext{
${ }^{7}$ Public capital should be broadly understood to include not only physical infrastructure (railroads, roads, airports, etc.), but also social services such as education and health.

${ }^{8}$ It is assumed that domestic households do not have access to world capital markets, so private foreign borrowing is zero. The assumption of no external financial market access approximates the non-concessional borrowing ceilings agreed between the government and the donors as well as major constraints faced by domestic private sectors of the low-income countries in their access to international capital markets. Given this, the appropriated income is introduced directly in the utility function (as in Svensson, 2000) because it does not contribute to the domestic economy. This consideration seems plausible since most of the misappropriated public funds are either consumed or secured abroad.
} 
rent appropriation is given by

$$
b_{i t}= \begin{cases}0 & \text { for } \quad e_{i t}=0 \\ \frac{e_{i t}}{e_{t}} b_{t} & \text { for } \quad e_{i t}>0\end{cases}
$$

where $e_{i t}=1-l_{i t}$ denotes the rent seeking effort of agent $i, e_{t}=\int_{0}^{1} e_{j t} \mathrm{~d} j$ the aggregate rent-seeking effort, and $b_{t}$ the total amount of public funds appropriated by rent-seekers.

At each date $t$, each agent $i$ must take two different decisions. First, she must allocate her time between rent seeking and productive activities; second, she must decide her consumption-saving plan. The objective of each agent $i$ is therefore to maximize her expected lifetime utility

$$
E_{0}\left(U_{i}\right)=E_{0} \sum_{t=0}^{\infty} \beta^{t} u\left(c_{i t}, b_{i t}\right)
$$

where $E_{0}$ is the expected value operator, $\beta \in(0,1)$ is the discount factor. The instantaneous utility function, $u(\cdot)$ is assumed to satisfy the Inada conditions.

\subsection{Government}

At each date $t$, the government invests $g_{t+1}$ in public infrastructure. ${ }^{9}$ To finance its expenses, the government levies a proportional tax on output at the rate

\footnotetext{
${ }^{9}$ Productive government infrastructure is modeled as a stock such that the aggregate stock of public capital at $t, g_{t}$, is not provided out of current output but results from past public investments (Irmen and Kuehnel, 2008).

Normally, the stock of public capital evolves according to $g_{t+1}=I_{t}^{g}+\left(1-\delta_{g}\right) g_{t}$, where $I_{t}^{g}$ denotes current public expenditures on infrastructure. For reasons of tractability, we assume full depreciation of public capital (i.e., $\delta_{g}=1$ ), such that $g_{t+1}$ denotes public investment as well.
} 
$\tau_{t}$ and receives windfall revenues from natural resource, $Z_{t}$, and from foreign aid, $A_{t}$, which can be a pure (untied) transfer or is tied to investment in public infrastructure. Following Chatterjee et al. (2003), Neanidis and Varvarigos (2009), and Borensztein et al. (2013) we assume that foreign aid disbursements and windfall from natural resources are measured in proportion of domestic income, such that:

$$
A_{t}=a_{t} y_{t} \equiv \bar{a} y_{t}, Z_{t}=z_{t} y_{t}
$$

where $y_{t}=\int_{0}^{1} y_{i t} \mathrm{~d} i$ is the aggregate output.

The windfall revenues from natural resources is highly volatile such that $\left\{z_{t}\right\}_{t \geq 0}$ is assumed to be a sequence of identically distributed random variables. More precisely, the exogenously determined resource revenue process $\left\{z_{t}\right\}_{t \geq 0}$ is assumed to be a linear Markov process given by

$$
z_{t}=(1-\rho) \bar{z}+\rho z_{t-1}+\varepsilon_{t}, \varepsilon_{t} \sim \text { i.i.d. }\left(0, \sigma_{\varepsilon}^{2}\right)
$$

where $\bar{z}$ is the average resource revenue (the steady state level of $z_{t}$ ) and $\rho \leq 1$ captures the persistence of the revenue process. For this specification, the variance of the process $\left\{z_{t}\right\}_{t \geqq 0}$ (using the invariant distribution) is given by $\sigma_{z}^{2}=\sigma_{\varepsilon}^{2} /(1-$ $\rho^{2}$ ). This dynamics of resource windfalls reflects both a possible upward trend (an increase in $\bar{z}$ if natural resource revenues increase) and volatility (an increase in $\left.\sigma_{z}\right) .^{10}$

To capture the donor disbursement policy in a more realistic way, it is further assumed that aid flow at time $t, a_{t}$, is indexed to the flow of resource revenue, $z_{t}$ :

\footnotetext{
${ }^{10}$ The volatility in resource revenues can be due to exogenous changes in either the price of the resource or the endowment of the resource.
} 
when resource revenue falls (goes up) below (above) its average level, aid flow to the recipient country is adjusted upwards (downwards), proportionately. More specifically, aid flows to the recipient country are given by:

$$
a_{t}=\bar{a}+\mu_{\bar{z}}\left(\bar{z}-z_{t}\right)
$$

$\bar{a}$ is the average level of aid flow, $\bar{z}$ is the average level of resource revenue and $\mu_{\bar{z}} \in$ $(0,1)$ is the adjustment coefficient that determines the degree of aid indexation. ${ }^{11}$

The government cannot issue debt claims and therefore is required to maintain a balanced budget each period. Thus, public capital evolves according to ${ }^{12}$

$$
g_{t+1}=\left[1-\phi\left(e_{t}\right)\right] p_{t}+\lambda a_{t} y_{t}
$$

where $p_{t}=\tau_{t} y_{t}+z_{t} y_{t}+(1-\lambda) a_{t} y_{t}$ is the government funds targeted by rentseekers, $\phi(e)$ is the share of government funds appropriated by agents engaging in rent seeking activities and $\lambda \in[0,1]$ represents the degree to which foreign aid contributes to the formation of public capital. ${ }^{13}$ Thus, the aggregate amount appro-

\footnotetext{
${ }^{11}$ The aim of indexing aid flows to some macroeconomic indicator of the recipient country's income is to reduce its macroeconomic volatility thereby stabilizing its income. Aid flows can be indexed to various indicators (terms of trade, GDP, etc.), each having advantages and inconveniences (see for example Dhasmana, 2008). Resource windfall indexed aid is chosen because resource revenue is mostly the main determinant of aggregate income in low-income resource rich countries. It should be expected that $\mu_{\bar{z}}$ increases with $\bar{z}$.

${ }^{12}$ We abstract from considerations of international borrowing to keep the analysis tightly focused on resource volatility. Nonetheless, this could be justified by evidence provided by Prati and Tressel (2006) who argue that the vast majority of aid recipient countries have accumulated very high levels of debt that severely restricts their capacity to borrow in international markets (see also Neanidis and Varvarigos, 2009).

${ }^{13} \lambda=0$ means Program aid (also referred to as budget or "untied" aid) which generally takes the form of a cash disbursement and is perfectly fungible. By contrast, $\lambda=1$ means project aid (or "tied" aid), consisting of transfers for investment projects agreed between the donor and the recipient country; whether it is fungible or not depends on whether, prior to the aid commitment, the recipient
} 
priated from government coffer is given by

$$
b_{t}=\phi\left(e_{t}\right) p_{t}=\phi\left(e_{t}\right)\left[\tau_{t}+z_{t}+(1-\lambda) a_{t}\right] y_{t}
$$

The function $\phi(\cdot)$ is such that $\phi^{\prime}(\cdot)>0$ and $\phi(e) \in[0,1)$ for all $e .^{14} \phi(\cdot)$ is assumed to be an increasing function of $e$, the aggregate rent seeking activity, to capture the idea that the quality of institutions in low-income resource-rich countries tends to decline during the periods of rapidly increasing government revenues. This is because in equilibrium, the aggregate rent-seeking effort may be positively related to government revenues. Therefore, an increase in government revenues would increase the aggregate rent-seeking effort $e$, thereby increasing $\phi\left(e_{t}\right)$, meaning a decrease in the quality of institution. ${ }^{15}$ To sustain an equilibrium of on-going growth (Barro, 1990), it is assumed that every period the government adjusts its policy such as to keep the rate of public investment constant at

$$
g_{t+1}=\bar{g} y_{t}
$$

Substituting (10) in the government budget constraint (8) yields the following tax

country intended to finance the project itself (Agénor and Aizenman, 2010). Tied aid is assumed to be secured from appropriation.

${ }^{14}$ Following Hodler (2007), $\phi$ may be interpreted as an inverse measure of institutional quality: The higher $\phi$ is, the poorer are the institutions that restrict appropriation of public funds by rent seekers.

\footnotetext{
${ }^{15}$ It is worth emphasizing that this feature of rent-seeking ignores the congestion effects in appropriation technology, whereby the marginal product of rent seeking ought to be lower, the higher the total amount of rent-seeking activity, as the amount of public funds available for each rent seeker to steal falls when everybody is stealing from it (see Mauro, 2004).
} 
rule

$$
\begin{aligned}
\tau_{t} & =\frac{\bar{g}-\lambda a_{t}}{1-\phi\left(e_{t}\right)}-z_{t}-(1-\lambda) a_{t} \\
& =\frac{\bar{g}}{1-\phi\left(e_{t}\right)}-z_{t}-a_{t}-\lambda a_{t} \frac{\phi\left(e_{t}\right)}{1-\phi\left(e_{t}\right)}
\end{aligned}
$$

This equation shows that windfall revenues may allow the government to substitute for domestic tax financing. In particular, the tax rate may be very low when aid is tied and used to co-finance public capital (i.e., $\lambda>0$ ).

\section{Private sector optimal decisions}

At each period $t$, agent $i$ considers public infrastructure $g_{t}$, aggregate rentseeking effort $e_{t}$, aggregate public funds appropriated $b_{t}$ and her current capital stock $k_{i t}$ as given. Then she allocates her time and chooses her consumption such as to maximize her expected utility, given in equation (4), subject to her initial capital endowment $k_{i 0}$ and the capital accumulation constraint (2). The Lagrangian for each individual $i$ maximization problem is:

$$
L_{i}=E_{0} \sum_{t=0}^{\infty} \beta^{t}\left\{u\left(c_{i t}, b_{i t}\right)+v_{i t}\left[\left(1-\tau_{t}\right) f\left(k_{i t}, g_{t}, l_{i t}\right)-c_{i t}-k_{i t+1}+\left(1-\delta_{k}\right) k_{i t}\right]\right\}
$$

where $v_{i t}$ is the shadow value of wealth and $f\left(k_{t}, g_{t}, l_{t}\right)=A k_{t}^{\alpha}\left(l_{t} g_{t}\right)^{1-\alpha}=y_{t}$. Her optimal choice is characterized by the following first-order conditions:

$$
\begin{gathered}
\frac{\partial L_{i}}{\partial c_{t}}: \frac{\partial u}{\partial c}(t)=v_{i t}, \\
\frac{\partial L_{i}}{\partial l_{t}}: \frac{b_{t}}{e_{t}} \frac{\partial u}{\partial b}(t)=v_{i t}\left(1-\tau_{t}\right) \frac{\partial f}{\partial l}(t),
\end{gathered}
$$




$$
\begin{gathered}
\frac{\partial L_{i}}{\partial k_{i t+1}}: \beta E_{t}\left(v_{i t+1} R_{i t+1}\right)=v_{i t} \\
\frac{\partial L_{i}}{\partial v_{i t}}: k_{i t+1}=\left(1-\tau_{t}\right) A k_{i t}^{\alpha}\left(l_{i t} g_{t}\right)^{1-\alpha}-c_{i t}+\left(1-\delta_{k}\right) k_{i t}
\end{gathered}
$$

where $R_{t}=\left(1-\tau_{t}\right) \alpha A k_{t}^{\alpha-1}\left(l_{t} g_{t}\right)^{1-\alpha}+1-\delta_{k} \equiv\left(1-\tau_{t}\right) \frac{\partial f}{\partial k}(t)+1-\delta_{k}$ and $E_{t}$ is the conditional expectation operator given the information available at time $t$. In addition, the transversality condition on capital, $\lim _{j \rightarrow \infty} E_{t}\left(\beta^{j} v_{t+j} k_{t+j+1}\right)=0$ must be satisfied.

Equation (12a) is the traditional condition equating the marginal utility of consumption to the shadow value of wealth. Equation (12b) equates the marginal benefit (marginal product of rent seeking times its marginal utility) with the shadow value of the after-tax marginal product of labor, which is the productive income foregone. Equation (12c) is the dynamic optimality condition, equating the marginal cost with the expected marginal benefit of an additional unit of private capital investment. Equations (12a) and (12c) can be summarized by equation (13) which is the usual Euler equation characterizing the intertemporal efficiency condition.

$$
\frac{\partial u}{\partial c}(t)=\beta E_{t}\left[\frac{\partial u}{\partial c}(t+1) R_{t+1}\right]
$$

For analytical tractability and to derive closed-form solutions, we will use the momentary utility $u(\cdot)=\ln (\cdot)$ and assume a full depreciation of physical capital, (i.e., $\left.\delta_{k}=1\right)$. We further assume that utility is separable so that $u\left(c_{t}, b_{t}\right)=\ln \left(c_{t}\right)+$ $\theta \ln \left(b_{t}\right)$, where $\theta>0$ represents the relative importance of misappropriated funds in utility. Using the logarithmic utility, the first order conditions are rewritten as: 


$$
\begin{gathered}
\frac{\partial L_{i}}{\partial c_{t}}: \frac{1}{c_{i t}}=v_{i t}, \\
\frac{\partial L_{i}}{\partial l_{t}}: \frac{\theta}{1-l_{i t}}=v_{i t}\left(1-\tau_{t}\right)(1-\alpha) \frac{y_{i t}}{l_{i t}} \\
\frac{\partial L_{i}}{\partial k_{i t+1}}: \beta E_{t}\left(v_{i t+1} R_{i t+1}\right)=v_{i t}, \\
\frac{\partial L_{i}}{\partial v_{i t}}: k_{i t+1}=\left(1-\tau_{t}\right) A k_{i t}^{\alpha}\left(l_{i t} g_{t}\right)^{1-\alpha}-c_{i t} .
\end{gathered}
$$

The Euler equation (13) can also be rewritten as

$$
\frac{1}{c_{i t}}=\beta E_{t}\left(\frac{1}{c_{i t+1}}\left(1-\tau_{t+1}\right) \alpha A k_{i t+1}^{\alpha-1}\left(l_{i t+1} g_{t+1}\right)^{1-\alpha}\right) .
$$

Multiplying both sides of equation (15) by $k_{i t+1}$ and using equation (14d) yields

$$
\frac{k_{i t+1}}{c_{i t}}=\alpha \beta+\alpha \beta E_{t}\left(\frac{k_{i t+2}}{c_{i t+1}}\right)
$$

Equation (16) is a first order stochastic difference equation which can be solved by the method of repeated substitution. Given the transversality condition on capital, $\lim _{j \rightarrow \infty} E_{t}\left(\beta^{j} k_{t+j+1} / c_{t+j}\right)=0$, one can infer that the solution to this first order stochastic difference equation is a constant, say $H$, such that $k_{i t+1} / c_{i t}=H$ for all $t$. Therefore, expression (16) can be rewritten as

$$
H=\alpha \beta+\alpha \beta H
$$


16 of 24

Expression (17) can be solved for $H=k_{i t+1} / c_{i t}$ to yield $^{16}$

$$
\frac{k_{i t+1}}{c_{i t}}=\frac{\alpha \beta}{1-\alpha \beta}
$$

Substituting equation (18) in (2), one can solve for $k_{i t+1}$ and derive the optimal private investment (saving) and consumption rates as

$$
\begin{gathered}
k_{i t+1}=\alpha \beta\left(1-\tau_{t}\right) y_{i t}=s_{i t}(\cdot) y_{i t} . \\
c_{i t}=(1-\alpha \beta)\left(1-\tau_{t}\right) y_{i t} .
\end{gathered}
$$

Combining equations (19b) and (14a), and substituting in (14b) determines the optimal level of labor and rent-seeking effort

$$
e_{i t}^{*}=\frac{\theta(1-\alpha \beta)}{\theta(1-\alpha \beta)+1-\alpha} \equiv e^{*} ; 1-e_{i t}^{*}=l_{i t}^{*}=\frac{1-\alpha}{\theta(1-\alpha \beta)+1-\alpha} \equiv l^{*}
$$

Equation (20) shows that each agent $i$ chooses the same rent-seeking effort $e^{*}$ overtime. Given that $k_{i 0}=k_{0}$, it follows that all agents produce the same output $y_{i 0}=y_{0}$, obtain the same rent $b_{i 0}=b_{0}$ and accumulate the same amount of capital at date 0 . Therefore, they choose again the same rent-seeking effort in the ensuing period. Repeating this reasoning infinitely, one can conclude that $e_{i t}^{*}=e^{*}, k_{i t}=k_{t}, c_{i t}=c_{t}$, $b_{i t}=b_{t}$ and $y_{i t}=y_{t}$ for all $i$ and $t$. Using the tax rule (11), optimum saving and

\footnotetext{
${ }^{16}$ This solution satisfies the transversality condition on capital and can be checked by direct substitution in the stochastic difference equation (16).
} 
17 of 24

consumption rates (19) can be rewritten as

$$
\begin{gathered}
k_{t+1}=\alpha \beta\left[1-\frac{\bar{g}}{1-\phi\left(e^{*}\right)}+z_{t}+a_{t}+\lambda a_{t} \frac{\phi\left(e^{*}\right)}{1-\phi\left(e^{*}\right)}\right] y_{t}=s_{t}(\cdot) y_{t} . \\
c_{t}=(1-\alpha \beta)\left[1-\frac{\bar{g}}{1-\phi\left(e^{*}\right)}+z_{t}+a_{t}+\lambda a_{t} \frac{\phi\left(e^{*}\right)}{1-\phi\left(e^{*}\right)}\right] y_{t} .
\end{gathered}
$$

From (21a), it immediately follows that $\partial s_{t}(\cdot) / \partial z_{t}>0$; hence, a temporary rise in the resource windfalls increases private capital accumulation. Intuitively, a temporary increase in resource windfalls provides more resources to the government budget that may allow a reduction in income tax rate (thereby leaving additional resources to individuals for both consumption and saving) or an increase in the provision of public infrastructure (thereby increasing the marginal productivity of private capital, again leading to a positive accumulation of private capital).

Using the fiscal rule (10) along with the saving rule (21a) in the $t+1$ variant of equation (1), we can derive the stochastic, endogenous growth rate of output as

$$
\frac{y_{t+1}}{y_{t}}=A(\alpha \beta)^{\alpha}\left(\bar{g} l^{*}\right)^{1-\alpha}\left[1-\frac{\bar{g}}{1-\phi\left(e^{*}\right)}+z_{t}+a_{t}+\lambda a_{t} \frac{\phi\left(e^{*}\right)}{1-\phi\left(e^{*}\right)}\right]^{\alpha},
$$

which, after substituting for $a_{t}$ from (7), can be rewritten as

$$
\frac{y_{t+1}}{y_{t}}=\Omega\left[v+z_{t}+\mu_{\bar{z}} w\left(\bar{z}-z_{t}\right)+w \bar{a}\right]^{\alpha}
$$

where $\Omega=A(\alpha \beta)^{\alpha}\left(\bar{g} l^{*}\right)^{1-\alpha}, v=1-\frac{\bar{g}}{1-\phi\left(e^{*}\right)}$ and $w=1+\lambda \frac{\phi\left(e^{*}\right)}{1-\phi\left(e^{*}\right)}$.

The temporary growth rate of output is a random variable with different realizations each period depending on different realizations of resource revenues shocks, $z_{t}$. The long-run growth rate of output, $\gamma_{\mathrm{y}}$, is the mean value obtaining by taking 
expectations on (22). This ultimately yields

$$
1+\gamma_{\mathrm{y}} \equiv \operatorname{Mean}\left(\frac{y_{t+1}}{y_{t}}\right)=\Omega E_{0}\left[\Delta\left(z_{t}\right)\right]
$$

where, the function $\Delta$ is defined by

$$
\Delta\left(z_{t}\right)=\left[v+z_{t}+\mu_{\bar{z}} w\left(\bar{z}-z_{t}\right)+w \bar{a}\right]^{\alpha} .
$$

From (24), $\frac{\partial \Delta}{\partial \phi}=-\frac{\bar{g}-\lambda \bar{a}}{\left[1-\phi\left(e^{*}\right)\right]^{2}}<0 .{ }^{17}$ Then, $\frac{\partial \gamma_{\mathrm{y}}}{\partial \phi}<0$, implying that a decrease in institutional quality, i.e., an increase in $\phi$ dampens growth. This is because low institutional quality makes rent-seeking relatively more attractive, entailing a decrease in labor inputs. Notice that the negative impact of weak institutional quality on growth is larger when aid is untied (i.e., $\lambda=0$ ). Accordingly, the negative impact of weak institutional quality may be mitigated if aid is tied and the contribution of aid to the formation of public capital is large, that is if $\lambda$ is highly positive.

It also follows from (24) that $\frac{\partial \Delta}{\partial z}>0$ and $\frac{\partial \Delta}{\partial a}>0$. Therefore, all else equal, an increase in windfall revenues (from natural resources or foreign aid) enhances growth. This is because abundance of windfall may induce the government to lower the tax rate thereby leaving private agents with higher disposable income allowing them to consume and to save more. The increase in saving translates to an increase in private investment and ultimately has a positive effect on output growth.

Essentially, equation (22) shows that the actual growth rate is a random variable. Hence, rather than growing at a constant rate, the economy exhibits over time temporary growth rates that depend on different realizations of resource windfall

\footnotetext{
${ }^{17}$ This is because $\bar{g}-\lambda \bar{a}>0$, which follows from equation (11), giving that the tax rate is required to be positive.
} 
shocks in different periods. From equations (23) and (24), it is straightforward to show that the long-run effects of the variability of windfall revenues on trend growth are negative.

Reducing overall volatility of revenues by making aid countercyclical with respect to the resource revenues helps to achieve higher trend growth. Indeed, it can be easily shown that higher volatility in resource revenues implies a lower expected growth rate in the long run. The intuition of these results goes as follows: recall from (21a) that a temporary increase in resource windfall has positive effect on investment and growth. However, noting that the specification in (24) is concave in $z_{t}$, the temporary rise in growth resulting from an increase in resource revenue is not as pronounced as the the reduction in growth resulting from a decrease in resource revenue of equal magnitude. Consequently, higher volatility in resource revenue on average has a negative impact on growth. ${ }^{18}$ In effect, the economy would be better off getting a constant amount of resource revenue with certainty than getting the same amount on average, but with a non-zero variance. The indexation of aid inflows to natural resource revenues may help to mitigate the negative impact of resource volatility.

\section{Policy implications}

What can we learn from this analysis for the purposes of aid instruments design? The key conclusion is that making aid countercyclical helps to achieve higher

\footnotetext{
${ }^{18}$ This can be better seen through the function $\Delta$. Indeed, $\alpha<1$ implies that the production technology exhibits a diminishing marginal productivity of both private and public capital. Therefore $\Delta$ is concave with respect to $z_{t}$, implying that volatile resource windfall reduces expected growth. This follows immediately from Jensen's inequality.
} 
economic growth, and so does conditioning disbursements on enhancement of public capital. We start from discussing how the latter objective can be achieved, and then look at how it can be combined with the former one.

Aid can enhance the stock of public capital in a number of ways, most effectively when multiple ways are applied simultaneously as there are important complementarities among them.

First, public capital in this context must not be thought of as only physical capital, and foreign aid which can enhance its stock is not limited to financing infrastructure projects. Investments in human capital through public spending on social services such as primary health care and primary education may have positive externalities in the developing countries, benefiting not only their direct recipients of these services. Hence, a portion of human capital produced by such investments can be thought of as public capital.

Second, aid may enhance public capital if it makes public spending on infrastructure and social services more effective by means of supporting policy reforms and institutional changes, such as strengthening fiscal rules and improvements in the budgeting process or in public financial management. Implementation of investment projects financed by the donors might be more efficient compared to the projects implemented by the recipient government on its own, for example because the donor's involvement may help to transfer new technologies to the economy or because use of the donor's procurement rules may reduce the costs of the project. However, the investment projects approach to foreign aid has its limitations. Since money is fungible, the government may offer the donors to finance the projects which it would have implemented anyway, and reallocate its own resources to other, less efficient or less benign uses. It may also fail to finance maintenance 
of the completed pieces of infrastructure.

Donors' support to improvements in policies and institutions governing public finance helps to reduce the magnitude of such problems. In "budget support" operations serving this purpose, disbursements are conditioned on implementation of pre-agreed changes and become a part of the country's budget. One way then to ensure that foreign aid is both countercyclical and helps to enhance the stock of public capital is to introduce elements of insurance in the design of both aid products financing investments in infrastructure and social services and supporting policy and institutional reforms. For the investment projects, this can be done through their co-financing by the government and the donors at a variable rate: if oil prices are low, the donors contribute more and the government contributes less; and the other way around if the oil prices are high. For the budget support operations, the fact of disbursement conditioned on changes in policies and institutions might be delayed for certain period (say, a year), and its amount might be conditioned on the average price of the relevant commodity during that period. In addition to reducing the risk of macroeconomic instability, such designs would help to tie-in some of the oil rents into more productive spending, thus also making unnecessary excessive accumulation of resources in the stabilization fund and reducing amount of resources otherwise available for rent-seeking.

Yet no design of aid products can ensure that the governance in a low-income resource-rich country does not deteriorate to the point when it substantially affects amounts of foreign aid which can be absorbed by the country's economy with reasonable efficiency. This is particularly true about the budget support operations where use of resources is subject to the country's own public financial management rules and institutions. To mitigate this problem, Dobronogov et al. (2014) propose 
another approach would be to adjust the level of program disbursements in response to resource shocks so that countercyclical aid flows provide a degree of insurance to the development program, which could include a range of budget support, project support and other instruments. This would complicate project agreements but it offers some advantages, especially in situations when the donor is not comfortable in providing the equivalent of budget support.

To conclude, if design of foreign aid programs and projects is tailored to specific circumstances of low-income resource-rich countries, the donors may have an opportunity to help their governments to use their resource revenues productively and to increase their overall envelop of fiscal resources without amplifying the risks of rent-seeking. The analysis in this paper offers some theoretical underpinnings for developing such products and programs. 
23 of 24

\section{References}

Agénor, P.-R., Aizenman, J., 2010. Aid volatility and poverty traps. Journal of Development Economics 91, 1-7.

Barro, R., 1990. Government spending in a simple model of endogenous growth. Journal of Political Economy 98 (5), S103-S125.

Borensztein, E., Jeanne, O., Sandri, D., 2013. Macro-hedging for commodity exporters. Journal of Development Economics 101, 105-116.

Chatterjee, S., Sakoulisb, G., Turnovsky, S. J., 2003. Unilateral capital transfers, public investment, and economic growth. European Economic Review 47, 1077 $-1103$.

Collier, P., 2006. Is aid oil? an analysis of whether africa can absorb more aid. World Development 34 (9), 1482-1497.

Collier, P., 2007. The Bottom Billion: Why the Poorest Countries are Failing and What Can Be Done About It. Oxford University Press.

Dhasmana, A., April 2008. Welfare gains of aid indexation in small open economies., IMF Working Paper 08/101.

Dobronogov, A., Gelb, A., Saldanha, F., 2014. How should donors respond to resource windfalls in poor countries? From aid to insurance., Policy Research Working Paper 6952, The World Bank.

Dornbusch, R., Edwards, S. (Eds.), 1991. The Macroeconomics of Populism in Latin America. University of Chicago Press.

Frankel, J., 2012. The natural resource curse: A survey of diagnoses and some prescriptions. In: Arezki, R., Pattillo, C., Quintyn, M., Zhu, M. (Eds.), Commodity Price Volatility and Inclusive Growth in Low-Income Countries. International Monetary Fund.

Hodler, R., 2007. Rent seeking and aid effectiveness. International Tax and Public Finance 14, 525-541.

Irmen, A., Kuehnel, J., May 2008. Productive government expenditure and economic growth., Discussion Paper Series No. 464, University of Heidelberg.

Lane, P., Tornell, A., 1996. Power, growth and the voracity effect. Journal of Economic Growth 1 (2), 213-241. 
Mauro, P., 2004. The persistence of corruption and slow economic growth. IMF Staff Papers 51 (1), 1-18.

Morrison, K., 2012. What can we learn about the "resource curse" from foreign aid? The World Bank Research Observer 27 (1), 52-73.

Neanidis, K. C., Varvarigos, D., 2009. The allocation of volatile aid and economic growth: Theory and evidence. European Journal of Political Economy $25,447-462$.

Perry, G., 2009. Beyond Lending: How Multilateral Development Banks Can Help Developing Countries Manage Volatility. Washington, DC: Center for Global Development.

Prati, A., Tressel, T., 2006. What is the most effective monetary policy for aidreceiving countries?, Working Paper no. 12, United Nations Department of Economic and Social Affairs.

Svensson, J., 2000. Foreign aid and rent-seeking. Journal of International Economics 51, 437-461.

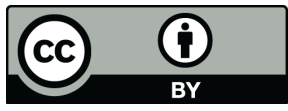

(C) 2016 by the authors; licensee Preprints, Basel, Switzerland. This article is an open access article distributed under the terms and conditions of the Creative Commons by Attribution (CC-BY) license (http://creativecommons.org/licenses/by/4.0/). 